\title{
Hyperglycinemia. V. The Miscible Pool and Turnover Rate of Glycine and the Formation of Serine *
}

\author{
William L. Nyhan and Barton Childs \\ (From the Departments of Pediatrics, the University of Miami School of Medicine, Miami, \\ Fla., and the Johns Hopkins University School of Medicine, Baltimore, Md.)
}

Hyperglycinemia is a disorder of amino acid metabolism characterized by abnormal concentrations of glycine in the blood, urine, and cerebrospinal fluid $(1,2)$. Prominent features of the disease have been mental retardation, neutropenia, thrombocytopenia, and osteoporosis with pathological fractures $(1,3)$. Recurrent episodes of ketosis and metabolic acidosis, progressing to coma, have constituted the earliest and most striking aspect of the disease $(1,3,4)$.

This study was designed to assess the turnover of glycine and pool size in a patient with hyperglycinemia and in suitable control individuals by using glycine-2- $\mathrm{H}^{3}$. We found that the miscible pool of glycine was considerably larger in the patient than in control children, and that the conversion of glycine to serine differed sufficiently in patient and controls to suggest the presence of a fundamental defect in this interconversion in hyperglycinemia.

\section{Methods}

Subjects. The patient with hyperglycinemia was the subject of the initial report (1). He was studied at ages 4 and $4 \frac{1}{2}$ years, and on both occasions his weight was $14.5 \mathrm{~kg}$ and his height $98 \mathrm{~cm}$. Control individuals were children with nonspecific mental retardation whose age, activity, and developmental level were similar to those of the patient (Table I). All were ambulatory except during the hour required for the experiment. Control children received a regular hospital diet. The patient received a special diet containing approximately $20 \mathrm{~g}$ of protein (3). Each subject received an intravenous injection of $30 \mu \mathrm{c}$ per $\mathrm{kg}$ of glycine- $2-\mathrm{H}^{3}$ in 1 to $4 \mathrm{ml}$ over a period of 1 to 2 minutes. Radiation dosage was calculated to be 0.036 rad.

Isotopic glycine. Glycine-2- $\mathrm{H}^{3} 1$ had a specific activity of $44 \mathrm{mc}$ per mmole. Radiochemical purity and stability of the label in glycine were repeatedly assessed

* Submitted for publication June 15, 1964; accepted August 28, 1964.

Aided by grants from the U. S. Public Health Service (AM07929 and GM05945).

1 New England Nuclear Corp., Boston, Mass. by column chromatography. Samples for injection were made isotonic with saline and sterilized by autoclaving.

Analytical methods. Samples of plasma were prepared as previously described (4) and subjected to chromatography on modified Moore-Stein columns (5). Fractions of 2.2 to $2.5 \mathrm{ml}$ were collected, and $1-\mathrm{ml}$ samples were removed from each and assayed for amino acid content by using the Ninhydrin reaction (4) and for radioactivity in a Packard Tri-Carb liquid scintillation spectrometer. Some samples were also analyzed for amino acid content with the Beckman-Spinco automatic amino acid analyzer (6). Counting was carried out in a dioxane-naphthalene system [naphthalene, $50 \mathrm{~g} ; 2,5-$ diphenyloxazole (PPO), $6 \mathrm{~g} ;$ 1,4-bis-2-(5-phenyloxazolyl benzene (POPOP), $0.1 \mathrm{~g}$; and 1,4-dioxane to 1.0 L] after making samples $0.035 \mathrm{~N}$ with $\mathrm{HCl}$. Efficiency was $3.7 \%$.

Stcady state. Subjects were fasting and thirsting during the experimental period. Determination of the plasma concentrations of glycine during the experiments indicated the presence of a steady state. Concentrations at various times differed from the mean glycine concentration by an average of $6.7 \%$. In another subject stability of the levels of plasma glycine was documented over an even longer period. Levels at 60, 120 , and 180 minutes after injection were $1.72,1.72$, and $1.74 \mathrm{mg}$ per $100 \mathrm{ml}$, respectively. It was therefore assumed that the rate of entry of glycine into the pool was equal to its rate of leaving the pool.

\section{Results}

Miscible pool of glycine and its rate of turnover. The specific activity of the glycine of the plasma fell rapidly after the intravenous injection of glycine-2- $\mathrm{H}^{3}$. Isotope was not detectable after 1 hour. Data obtained on the patient and on a control are illustrated in Figure 1. Similar curves were found in a second experiment on the patient and in the other three controls. In each case there was a rapid initial decline that was interpreted as initial mixing in the miscible pool. The second slope, which began after 10 minutes, was taken to represent the rate of turnover of the pool. In each case, the semilogarithmic plot of this second curve yielded a straight line. 
TABLE I

Miscible pool of glycine and turnover rate*

\begin{tabular}{|c|c|c|c|c|c|c|c|c|c|c|c|}
\hline \multirow[b]{2}{*}{ Subject } & \multirow[b]{2}{*}{ Wt } & \multirow[b]{2}{*}{ BSA } & \multicolumn{2}{|c|}{ Dose injected } & \multirow{2}{*}{$\begin{array}{l}\text { Intercept } \\
\text { (Io) }\end{array}$} & \multicolumn{3}{|c|}{ Miscible pool } & \multirow{2}{*}{$\begin{array}{l}\text { Mean } \\
\text { plasma } \\
\text { glycine }\end{array}$} & \multirow{2}{*}{$\begin{array}{l}\text { Slope } \\
(\mathrm{K})\end{array}$} & \multirow{2}{*}{$\begin{array}{l}\text { Turn- } \\
\text { over } \\
\text { (KA) }\end{array}$} \\
\hline & & & (a) & & & (A) & (A) & (A) & & & \\
\hline & $k g$ & $m^{2}$ & $\mu g$ & $\underset{10^{-6}}{c p m} \times$ & $\underset{\mu m o l e}{c p m / ~}$ & $m g$ & $m g / k g$ & $m g / m^{2}$ & $\mathrm{mg} / 100 \mathrm{ml}$ & $\min ^{-1}$ & $\mathrm{~g} / 24 \mathrm{hrs}$ \\
\hline \multirow{2}{*}{ Patient } & \multirow{2}{*}{14.5} & \multirow{2}{*}{0.63} & \multirow{2}{*}{745} & \multirow{2}{*}{34.0} & 6,870 & 370 & 25.2 & 590 & 7.3 & 0.0336 & 17.9 \\
\hline & & & & & 5,930 & 429 & 29.6 & 680 & 3.8 & 0.0378 & 23.3 \\
\hline Control A & 11.8 & 0.54 & 601 & 27.4 & 15,500 & 132 & 11.2 & 244 & 2.0 & 0.0387 & 7.3 \\
\hline Control G & 8.3 & 0.46 & 425 & 19.4 & 9,160 & 158 & 19.1 & 353 & 1.1 & 0.0474 & 10.8 \\
\hline Control L & 19.4 & 0.75 & 990 & 45.3 & 11,340 & 297 & 15.3 & 396 & 1.3 & 0.0341 & 14.5 \\
\hline Control B & 11.5 & 0.55 & 585 & 26.8 & 8.840 & 225 & 19.5 & 410 & 1.7 & 0.0387 & 14.8 \\
\hline
\end{tabular}

* Pool sizes were calculated from the equation $\mathrm{A}=\mathrm{a}[(\mathrm{Ii} / \mathrm{Io})-1]$ in which $\mathrm{Ii}$ is the specific activity of the isotope administered $(3.42 \times 106$ cpm per $\mu$ mole).

Visual comparison of the two experiments illustrated in Figure 1 suggests that the pool size is larger in the patient, but that the rates of turnover are similar. The slopes of the second or linear portions of the curves and their intercepts at zero time were calculated by the method of least squares for each experiment ${ }^{2}$ (Table I). Pool sizes were calculated by a standard isotope dilution formula (7).

The mean pool size in the patient was $400 \mathrm{mg}$, and that of the controls was $203 \mathrm{mg}$. This difference was significant statistically $(t=3.370, \mathrm{p}<$ $0.05)$. Correction of pool sizes for the size of the individual studied yielded pool sizes of $27.6 \mathrm{mg}$ per $\mathrm{kg}$ of body weight and $635 \mathrm{mg}$ per $\mathrm{m}^{2}$ of body surface in the patient, and $16.3 \mathrm{mg}$ per $\mathrm{kg}$ and 351 $\mathrm{mg}$ per $\mathrm{m}^{2}$ in controls. These differences were also significant at the $5 \%$ level.

The theoretic concentration that would result if the glycine of the total pool were uniformly distributed throughout the body water, estimated at $70 \%$ of the body weight, was calculated (7). Comparison with plasma levels indicated volumes of distribution in controls and in the second experiment on the patient that were somewhat greater than $70 \%$ of the body weight. These data suggest that distribution is not uniform, and intracellular areas contain greater concentrations than that of the extracellular space, which is consistent with information on the concentration of glycine in tissues. On the other hand, at the time of the first study, when dietary control in the patient was less careful and the plasma level was much higher, a volume of distri-

2 Statistical methods employed in this study were those described by Snedecor (8). bution approximating $35 \%$ was apparent. These data suggest that distribution of glycine may be altered in hyperglycinemia under conditions in which concentrations of glycine are very high. This conclusion is also consistent with data obtained on loading with substrate quantities of glycine (1).

Turnover of glycine was assessed by comparison of the slopes of the individual lines (Table I). In patient and controls, turnovers were 0.036 and 0.039 pools per minute, respectively, or approximately 2 pools per hour. Comparison of the $95 \%$ confidence limits of the slopes revealed close overlap among the controls. Least square lines were then calculated to include all the data for controls and both experiments on the patient (Figure 2). The overlap between the confidence limits of the two slopes is indicated in the legend. It was therefore concluded that the slopes representing turnover in the two populations did not differ significantly. On the other hand, differences in the sizes of the pool were such that turnover considered in grams of glycine per day (Table I) was considerably greater in the patient. $\mathrm{He}$ had a mean turnover of $20.6 \mathrm{~g}$ of glycine per 24 hours, whereas in controls the mean value was $11.9 \mathrm{~g}$ per 24 hours.

Formation of serine from glycine. In the course of these studies all of the amino acids separated on the $150-\mathrm{cm}$ column were examined for radioactivity. Only serine was found to be labeled. The specific activities of the serine of the plasma of the patient and two control individuals are illustrated in Figure 3. Similar patterns were observed in the other experiments, and comparative data for the six experiments carried out are 

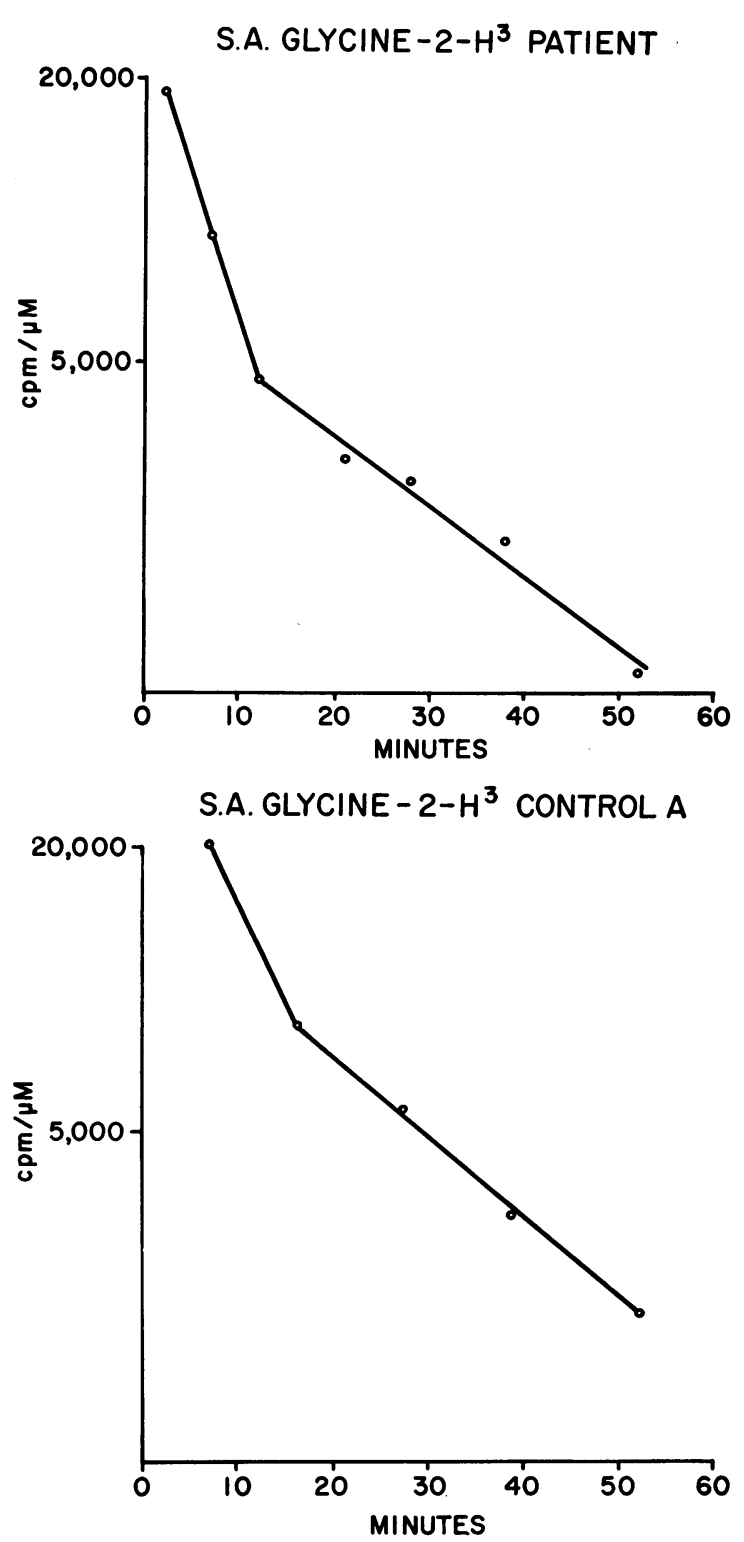

Fig. 1. Specific activities of glycine. Semilogarithmic plot of the concentration of isotope in the glycine in the plasma of the patient and one control after intravenous injection of glycine- $2-\mathrm{H}^{3}$.

given in Table II. In controls the conversion of glycine to serine was very rapid. The specific activity was found to decline from peak levels as early as 7 minutes after injection. A rise in specific activity from a 2 -minute specimen to one obtained at 9 minutes was found in control $\mathrm{L}$. The shape of the curve obtained in the patient was quite different from those of controls, indicating a considerably slower formation of serine from glycine. It was predominantly because of this difference between patient and controls that a second experiment was carried out on the patient. An even flatter curve than the one illustrated was obtained. Between 10 and 20 minutes the specific activities obtained in the first and second experiments were 235 and $250 \mathrm{cpm}$ per $\mu$ mole, respectively, at 40 minutes they were 270 and 200, and at 28 minutes they were 365 and $240 \mathrm{cpm}$ per $\mu$ mole, respectively. Concentrations of serine in the plasma of the patient were 2.58 and $1.59 \mathrm{mg}$ per $100 \mathrm{ml}$ in the first and second experiments. These values were not very different from those of $1.88,1.52,1.11$, and $1.82 \mathrm{mg}$ per $100 \mathrm{ml}$ found in controls.

The specific activities of serine in the patient (Table II) were considerably lower than those of controls as late as 17 minutes after the injection of the tracer, indicating the magnitude of earlier differences. On the other hand, differences observed at 40 minutes were small. This is consistent with the concept that the over-all metabo-

\section{CALCULATED S.A. GLYCINE IN PLASMA}

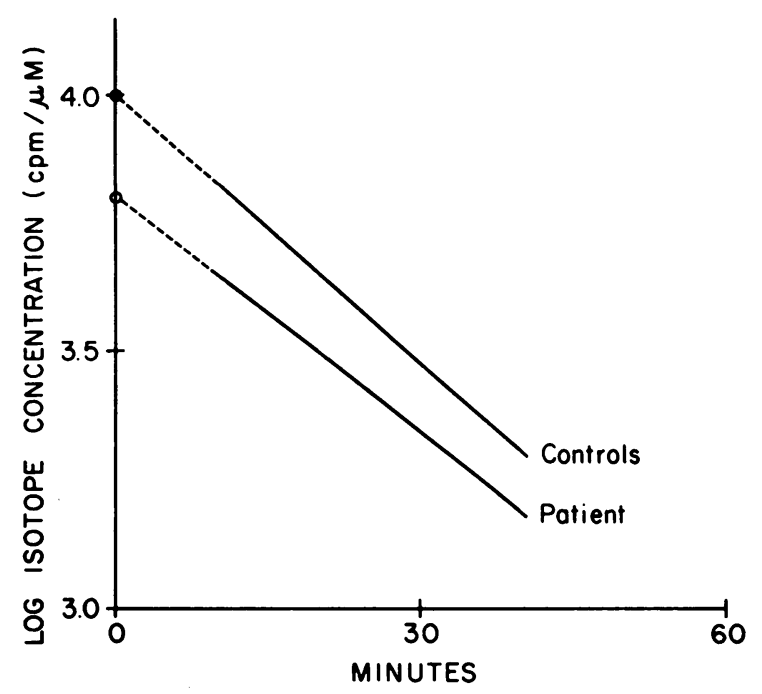

Fig. 2. Specific activities of glycine in plasma. Lines were calculated by the method of least squares for all of the specific activities at all of the time points in controls and for the two experiments on the patient. The single line obtained for each group has been connected to the intercept by a broken line. The lines were expressed as $y=a+b x$ in which $a$ represents the intercept and the data for $b$, the slope, its variance; $95 \%$ confidence limits were as follows:

$\begin{array}{lccl} & b & \pm \mathrm{SE}_{b} & \pm t_{0.05} \mathrm{SE}_{b} \\ \text { Patient } & -0.0154 & 0.0019 & 0.0044 \\ \text { Controls } & -0.0175 & 0.0023 & 0.0049\end{array}$




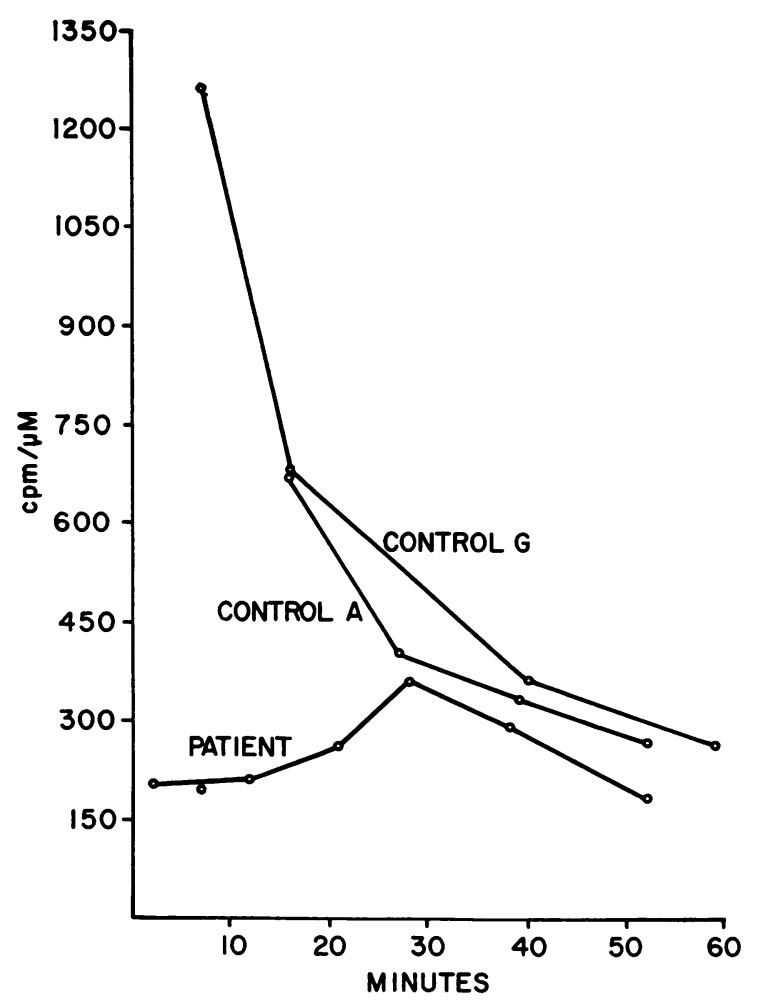

Fig. 3. Conversion of glycine to Serine. Specific activities of the serine isolated from the plasma after the intravenous injection of glycine- $2-\mathrm{H}^{3}$. Data represented are those obtained on the patient and two control individuals.

lism of serine, once formed, is not different in patient and controls. These experiments were interpreted to indicate a major defect in the patient with hyperglycinemia in the conversion of glycine to serine.

\section{Discussion}

The use of isotopic methods to study the pool size and turnover rate of a metabolite involves a

TABLE II

Specific activities of serine after injection of glycine-2- $H^{3 *}$

\begin{tabular}{lccl}
\hline \hline & No. & $\begin{array}{c}\text { cpm/ } / \mu \text { mole } \\
\text { serine at } \\
17 \mathrm{~min}\end{array}$ & $\begin{array}{c}\mathrm{cpm} / \mu \mathrm{mole} \\
\text { serine at } \\
40 \mathrm{~min}\end{array}$ \\
\hline Patient & 2 & 235,250 & 200,270 \\
Controls & 4 & $621 \pm 53$ & $340 \pm 41$
\end{tabular}

* The data represent two experiments on the patient and one experiment on each of four control individuals. The values for the controls are the mean specific activities \pm their standard errors, and for the patient the individual specific activities are given. number of assumptions. An essential starting point is that the compound whose radioactivity is to be measured is clearly separated from other compounds and that its quantity can be determined with precision. The fulfillment of these criteria for ion exchange chromatography of glycine has been established by Moore and associates $(5,6)$. The assumption of a steady state was tested in this study by determination of concentrations of glycine in plasma throughout the experimental period. The use of the plasma for direct measurement of specific activity obviates some of the assumptions required when the urine is employed to assess the specific activities of body pools. It is also implicit in the method that the compound is freely diffusible in the body and that it mixes completely and immediately with all of the compound in the body pool. The establishment of linear fall in specific activity when its logarithm is plotted against time has been interpreted as supporting the validity of these assumptions $(7,9$, 10). Linearity throughout the period of study has been observed with regularity in studies of uric acid turnover, in which the uric acid studied is obtained from the urine $(7,11)$. Studies in which the plasma is sampled at early time points after injection (12), however, have revealed an initial steep decline suggesting that mixing requires a finite period after injection, which might be as long as 20 minutes. In these studies, this early change in the specific activity of glycine was over within 10 minutes of injection. These considerations indicate the approximate nature of these estimations of pool size. The rate of mixing of glycine in the pool is rapid in contrast to its rate of turnover, but it is certainly not immediate. Large errors in the estimation of the true pool could result in this way. However, it appears likely (12) that if plasma were assessed in the early minutes after injection, a finite mixing period would be always encountered. Therefore, this is probably a general criticism of the pool size concept. The method employed provides the simplest method of comparing the pools of patient and controls and should have internal validity.

Furthermore, it appears appropriate in the case of glycine to utilize the simplest approximation of the data obtained rather than to employ a more 
elaborate compartmental analysis, for there is considerable evidence to indicate that there are a number of different glycine pools. Studies in progress in this laboratory indicate different concentrations of free glycine in different tissues of children, all of which exceed those of the plasma. Evidence for different functional pools for glycine was provided by Weissbach and Sprinson (13), who compared specific activities in glycine isolated as urinary hippurate from that of the glycine of tissue proteins, and by Watts and Crawhall (14), who found differences between free urinary glycine and the glycine of urinary hippurate.

The finding that the size of the glycine pool in the patient studied approximated twice that of controls is intuitively reasonable, for elevated concentrations of glycine have been found in blood, urine, cerebrospinal fluid, and tissues. Furthermore, two experiments carried out on the same patient under different conditions of control, in which there was an almost twofold difference in plasma concentrations of glycine, yielded similar values for the size of the pool. These data indicate that plasma concentration alone is not an adequate reflection of the size of the pool and at the same time suggest the consistency of the method.

Turnover rates were also similar in the two experiments on the same patient. Turnover rates, in pools per unit time, were also quite similar in patient and controls. Because of the difference in pool size, however, the number of grams of glycine turned over by the patient each day was approximately twice that found in the controls. The turnover of glycine was studied by Watts and Crawhall (14) in a 72-kg man, in whom the concentration of isotope in glycine was assayed in the urine after isotopic glycine was administered by mouth. A turnover rate of 0.59 mmole per $\mathrm{kg}$ per hour was reported. The turnover of 11.9 $\mathrm{g}$ per $\mathrm{kg}$ per 24 hours found in the control children in the present study amounts to 0.66 mmole per kg per hour. Similarly, Arnstein and Neuberger (15) reported glycine turnover in the rat of 1 mmole per $\mathrm{kg}$ per hour in experiments in which the specific activities of the glycine of tissue proteins were measured after feeding of isotopic glycine. The similarity of the orders of magnitude obtained in three quite different experiments on two mammalian species is striking.

The formation of serine from glycine in the patient with hyperglycinemia was sufficiently different from that of controls to suggest a fundamental abnormality in the conversion of glycine to serine. The amounts of injected glycine that could be found in serine were closely duplicated in the two experiments that were carried out on the patient at the times when his plasma concentrations of glycine differed by a factor of almost two and plasma concentrations of serine by 1.6. These data, as well as the similarity in glycine pool size and turnover under these different conditions, and the close similarity of serine concentrations in patient and controls render less likely the possibility that differences observed could reflect problems of distribution in a larger pool. At 17 minutes the specific activity of serine in the controls was twice as great as that of the patient, which is of the order of magnitude of the differences in pool size, but at 7 to 10 minutes, sixfold differences were observed. Dietary differences between patient and controls appear to be a necessary defect in the design of these experiments, for patients with hyperglycinemia cannot be given a normal diet without an extreme alteration of homeostasis (1-4), and the diet evolved for this patient appears to be quite unpalatable to other children. Conduct of the experiment in the fasting state should minimize these differences. The data obtained could reflect an alteration in enzyme activity in which an enzyme active in controls was present in markedly diminished activity in the disorder under study. Alternatively, the conversion of glycine to serine could result in vivo from the action of more than one enzyme or enzymatic pathway. Deletion of the major pathway could account for the findings. Alternative pathways are known for the interconversion of glycine and serine. One of these pathways could represent the major route of glycine catabolism. From the point of view of synthesis, it is currently considered (16) that most of the glycine synthesized is made from serine, whereas serine is produced predominantly from intermediates of carbohydrate metabolism. The conversion of glycine to serine may, therefore, be of minor importance in the total synthesis of serine. It may, however, be crucial for the degradation of glycine. 


\section{Summary}

The metabolism of glycine has been studied in a patient with idiopathic hyperglycinemia and in four control individuals by using glycine- $2-\mathrm{H}^{3}$. The size of the glycine pool in the patient was approximately twice as large as that of controls. The rates at which these pools turned over were similar, so that total turnover amounted to twice as many grams of glycine each day in the patient as in the controls. Among the amino acids other than glycine, only serine was found to be labeled. The formation of serine from glycine was markedly less efficient in the patient. These data suggest that there is a fundamental abnormality in hyperglycinemia in the conversion of glycine to serine.

\section{References}

1. Childs, B., W. L. Nyhan, M. Borden, L. Bard, and R. E. Cooke. Idiopathic hyperglycinemia and hyperglycinuria: a new disorder of amino acid metabolism. I. Pediatrics 1961, 27, 522.

2. Nyhan, W. L., J. J. Chisolm, Jr., and R. O. Edwards, Jr. Idiopathic hyperglycinuria. III. Report of a second case. J. Pediat. 1963, 62, 540.

3. Childs, B., and W. L. Nyhan. Further observations of a patient with hyperglycinemia. Pediatrics 1964, 33, 403.

4. Nyhan, W. L., M. Borden, and B. Childs. Idiopathic hyperglycinemia: a new disorder of amino acid metabolism. II. The concentrations of other amino acids in the plasma and their modification by the administration of leucine. Pediatrics 1961, 27,539 .
5. Moore, S., D. H. Spackman, and II. H. Stein. Chromatography of amino acids on sulfonated polystyrene resins. An improved system. Analyt. Chem. 1958, 30, 1185.

6. Spackman, D. H., W. H. Stein, and S. Moore. Automatic recording apparatus for use in the chromatography of amino acids. Analyt. Chem. 1958, 30, 1190.

7. Benedict, J. D., P. H. Forsham, and D. Stetten, Jr. The metabolism of uric acid in the normal and gouty human studied with the aid of isotopic uric acid. J. biol. Chem. 1949, 181, 183.

8. Snedecor, G. W. Statistical Methods. Ames, Iowa, Iowa State College Press, 1956.

9. Bishop, C., W. Garner, and J. H. Talbott. Pool size, turnover rate, and rapidity of equilibration of injected isotopic uric acid in normal and pathological subjects. J. clin. Invest. 1951, 30, 879.

10. Wyngaarden, J. B. The effect of phenylbutazone on uric acid metabolism in two normal subjects. J. clin. Invest. 1955, 34, 256.

11. Lesch, M., and W. L. Nyhan. A familial disorder of uric acid metabolism and central nervous system function. Amer. J. Med. 1964, 36, 561.

12. Peterson, R. E., and J. B. Wyngaarden. The miscible pool and turnover rate of hydrocortisone in man. J. clin. Invest. 1956, 35, 552.

13. Weissbach, A., and D. B. Sprinson. The metabolism of 2-carbon compounds related to glycine. I. Glyoxylic acid. J. biol. Chem. 1953, 203, 1023.

14. Watts, R. W. E., and J. C. Crawhall. The first glycine metabolic pool in man. Biochem. J. 1959, 73, 277.

15. Arnstein, H. R. V., and A. Neuberger. The synthesis of glycine and serine by the rat. Biochem. J. 1953, 55, 271.

16. Neuberger, A. Aspects of the metabolism of glycine and of porphyrins. Biochem. J. 1961, 78, 1. 